\title{
Activation of peroxisome proliferator-activated receptor $\gamma$ ameliorates monocrotaline-induced pulmonary arterial hypertension in rats
}

\author{
XINMING XIE ${ }^{1}$, GUIZUO WANG ${ }^{2}$, DEXIN ZHANG ${ }^{1}$, YONGHONG ZHANG ${ }^{1}$, \\ YANTING ZHU ${ }^{1}$, FANGWEI LI ${ }^{1}$, SHAOJUN LI ${ }^{1}$ and MANXIANG LI ${ }^{1}$ \\ ${ }^{1}$ Department of Respiratory Medicine, The First Affiliated Hospital of Medical College, \\ Xi'an Jiaotong University, Xi'an, Shaanxi 710061; ${ }^{2}$ Department of Respiratory Medicine, \\ Shaanxi Provincial People's Hospital, Xi'an, Shaanxi 710068, P.R. China
}

Received March 9, 2015; Accepted May 5, 2015

DOI: $10.3892 /$ br.2015.465

\begin{abstract}
Activation of peroxisome proliferator-activated receptor $\gamma(\operatorname{PPAR} \gamma)$ suppresses the proliferation of pulmonary artery smooth muscle cells (PASMCs) and vascular remodeling in rats and humans, and therefore improves the development of pulmonary arterial hypertension (PAH). However, molecular mechanisms underlying these effects have not been completely understood. In the present study, the effects of PPAR $\gamma$ activation in monocrotaline (MCT)-induced pulmonary artery remodeling in rats were investigated. Eighteen Sprague-Dawley (SD) rats were randomly assigned into three groups $(\mathrm{n}=6)$ : Control (Con), $\mathrm{PAH}$ and PAH treated with rosiglitazone (MCT + Rosi). The right ventricular systolic pressure (RVSP), the ratio of the right to left ventricle plus septum weight $[\mathrm{RV} /(\mathrm{LV}+\mathrm{S})]$, the percentage of medial wall thickness (\%MT) and wall area (\%WA) were used to evaluate the development of PAH. Tissue morphology was measured using hematoxylin and eosin staining. The protein levels of the phosphatase and tensin homologue deleted on chromosome ten (PTEN), Akt (ser473) phosphorylation (p-Akt) and total Akt in intrapulmonary arteries were determined by western blot analysis. MCT treatment significantly increased the RVSP, which was reduced by rosiglitazone treatment. The ratio of $\mathrm{RV} /(\mathrm{LV}+\mathrm{S}), \% \mathrm{MT}$ and \%WA induced by MCT were similarly inhibited, which was associated with the increase of PTEN expression and the inhibition of Akt phosphorylation levels by rosiglitazone. In conclusion, activation of PPAR $\gamma$ ameliorates the proliferation of PASMCs and vascular remodeling by
\end{abstract}

Correspondence to: Dr Manxiang Li, Department of Respiratory Medicine, The First Affiliated Hospital of Medical College, Xi'an Jiaotong University, 277 West Yanta Road, Xi'an, Shaanxi 710061, P.R. China

E-mail: manxiangli@hotmail.com

Key words: pulmonary arterial hypertension, peroxisome proliferator-activated receptor $\gamma$, phosphatase and tensin homologue deleted on chromosome ten, vascular remodeling, proliferation regulating the PTEN/PI3K/Akt pathway, suggesting that the activation of PPAR $\gamma$ has potential benefits for PAH.

\section{Introduction}

Pulmonary arterial hypertension (PAH) is a common clinical condition with a range of underlying etiologies characterized by pathological changes in the pulmonary arteries, which lead to significant increases in the pulmonary arterial pressure (PAP) and in the right ventricular hypertrophy (RVH). There is no cure for this disease and medical regimens are limited. All forms of PAH share a common pathogenesis characterized by vasoconstriction, pulmonary vascular remodeling and thrombosis in situ (1). Vascular remodeling is majorly caused by pulmonary artery smooth muscle cell (PASMCs) proliferation and migration, which is critical to the pathogenesis of $\mathrm{PAH}$, however, the mechanism of pulmonary vascular remodeling is incompletely understood. Therefore, preventing or treating the development of PAH via the inhibition of pulmonary vascular remodeling is an important strategy.

Peroxisome proliferator-activated receptor $\gamma(\operatorname{PPAR} \gamma)$ is a family member of nuclear receptors, which consists of PPAR $\alpha$, PPAR $\beta$ (also known as PPAR 8 ) and PPAR $\gamma$, and previous studies have suggested that PPAR $\gamma$ has broad protective effects on the cardiovascular system that surpass the regulation of adipogenesis and glucose metabolism (2-5). Activation of PPAR $\gamma$ plays an important role in anti-inflammation, anti-proliferation and anti-fibrosis, suggesting that activation of PPAR $\gamma$ may benefit a variety of diseases (6-8). Evidence has been accumulating that activation of PPAR $\gamma$ may be a novel PAH therapeutic target. Studies have indicated that activation of PPAR $\gamma$ by rosiglitazone (Rosi), one of the most potent and selective synthetic agonists of PPAR $\gamma$ receptors, protects against $\mathrm{PAH}$ development in a series of experimental models (9). However, the mechanisms underlying the inhibition of proliferation of PASMCs by activation of PPAR $\gamma$ have not been completely understood; therefore hemodynamic, histology and immunoblotting were performed in the present study to test whether the activation of PPAR $\gamma$ inhibits monocrotaline (MCT)-induced PAH in rats. 


\section{Materials and methods}

Animals. Male Sprague-Dawley (SD) rats (250-350 g) were purchased from the animal center of the Xi'an Jiaotong University Medical College (Xi'an, China). The protocol of the study was approved by the Institutional Ethics Committee of Xi'an Jiaotong University Health Science Center and complied with the Declaration of the National Institutes of Health Guide for Care and Use of Laboratory Animals (publication no. 85-23, revised 1985). All the animals were housed in climate-controlled conditions with a 12 -h light:12-h dark cycle and had free access to chow and water.

Experimental protocols. The $18 \mathrm{SD}$ (7-week-old) rats were randomly divided into three groups ( $\mathrm{n}=6$ in each group). Models of PAH rats were induced by subcutaneous injection of MCT (60 mg/kg; Sigma, St. Louis, MO, USA) on day 1, and another group model of PAH rats were orally administered Rosi $(5 \mathrm{mg} / \mathrm{kg} / \mathrm{day}$; GlaxoSmithKline, London, UK) for 4 weeks until the rats were sacrificed. The control rats were subcutaneously injected with normal saline and orally administered the same volume of saline.

Measurement of the right ventricular systolic pressure (RVSP) and $R V H$. At day 28 , rats were anesthetized with $10 \%$ chloral hydrate $(0.3 \mathrm{ml} / \mathrm{kg}$, intraperitoneal injection). Following stable anesthesia, the right jugular vein was exposed and a polyethylene catheter (PE50) was inserted into the right atrium and right ventricle (RV) and the RVSP was monitored using a Grass polygraph (PowerLab; AD Instruments, Sydney, Australia). RVSP was assumed to be equal to the PAP in the presence of a normal pulmonary valve. The analog signals of pressure were digitized with a sampling frequency of $1,000 \mathrm{~Hz}$ and expressed in millimeters of mercury. The RVH was routinely checked to observe the establishment of PAH in the MCT-treated rats, which was assessed by the ratio of the weight of the right ventricle to that of the left ventricle plus septum: RV/(LV + S).

Tissue preparation and morphometric analysis of the pulmonary vessels. The rats were sacrificed following homodynamic measurements and the lungs were harvested. The right lungs were fixed in $4 \%$ paraformaldehyde overnight, sectioned at $5-\mu \mathrm{m}$ and stained with hematoxylin and eosin (H\&E). Explants of intrapulmonary arteries were isolated from the left lungs and stored at $-80^{\circ} \mathrm{C}$ for future use.

Pulmonary vascular remodeling was evaluated by determining the percentage medial wall thickness (\%MT) and wall area (\%WA) of vessels (diameter, 50-200 $\mu \mathrm{m}$ ) according to the method by Ochoa et al (10) and Wang et al (11). The medial thickness of the vessel wall is defined as the distance between inner and outer elastic lamina. Vessel external diameter (ED), lumen internal area (IA) and average total vessel area (TA) were examined. The \%MT was calculated as (2MT/ED) x 100 and \%WA was calculated as (TA - IA)/TA x 100. All the analyses were performed in a blinded manner.

Western blotting. Lung tissues were lysed in radioimmunoprecipitation assay lysis buffer [50 mM Tris (pH 7.4), $150 \mathrm{mM}$ $\mathrm{NaCl}, 1 \% \mathrm{NP} 40,0.5 \%$ sodium deoxycholate, $0.1 \%$ SDS, $1 \mathrm{mM}$
EDTA, $1 \mathrm{mM}$ phenyl-methylsulfonyl fluoride, $1 \mathrm{mM} \mathrm{Na}_{3} \mathrm{VO}_{4}$, $1 \mathrm{mM} \mathrm{NaF}$ and proteinase inhibitors]. Lysates were centrifuged at $13,000 \mathrm{rpm}$ at $4^{\circ} \mathrm{C}$ for $15 \mathrm{~min}$ and the supernatant was collected as total protein. The protein concentrations were measured using Pierce BCA protein assay kit (Thermo Fisher Scientific, Inc., Waltham, MA, USA). Protein was separated on SDS-PAGE gel and transferred onto a Trans-Blot nitrocellulose membrane (Bio-Rad, Hercules, CA, USA). Polyclonal antibodies against phosphatase and tensin homologue deleted on chromosome ten (PTEN; 9188S), p-Akt (13038S), total Akt (8596S; all Cell Signaling Technologies, Danvers, MA, USA) and rabbit anti-rat GAPDH (ABS16; Chemicon International, Inc., Billerica, MA, USA) (1:1,000 dilution) were used according to the manufacturer's instructions. Subsequently, the membrane was incubated with horseradish peroxidase conjugated with goat anti-rabbit IgG antibody (A0545; Sigma) (1:5,000 dilution), and reactions were developed with SuperSignal West Pico Chemiluminescent Substrate (Pierce Biotechnology, Inc., Rockford, IL, USA) and exposed to autoradiographic film. Signaling was quantified from scanned films using Quality One software (Bio-Rad).

Statistics analysis. Values are presented as mean \pm standard error of the mean. SPSS 13.0 software (SPSS, Inc., Chicago, IL, USA) processing was used for statistical analysis. Data were analyzed using one-way analysis of variance followed by Tukey post hoc test analysis of variance. $\mathrm{P}<0.05$ was considered to indicate a statistically significant difference between groups.

\section{Results}

Activation of PPAR $\gamma$ inhibits MCT-induced PAH. To examine whether activation of PPAR $\gamma$ suppresses the development of PAH in rats induced by MCT, RVSP and the weight ratio of $\mathrm{RV} /(\mathrm{LV}+\mathrm{S})$ were examined. As shown in Fig. 1 , RVSP was significantly increased in MCT-treated rats $(40.32 \pm 3.44 \mathrm{mmHg})$ compared with the control rats $(22.34 \pm 2.55 \mathrm{mmHg} ; \mathrm{P}<0.05)$, and this was accompanied with the increased ratio of $\mathrm{RV} /(\mathrm{LV}+\mathrm{S})$. The ratio of $\mathrm{RV} /(\mathrm{LV}+\mathrm{S})$ in the model of PAH $(0.45 \pm 0.03)$ was significantly increased compared with that in the control rats $(0.15 \pm 0.02 ; \mathrm{P}<0.01)$. However, treatment of the PAH model with the PPAR $\gamma$ agonist rosiglitazone for 4 weeks reduced the RVSP $(32.44 \pm 3.12 \mathrm{mmHg} ; \mathrm{P}<0.05$ vs. MCT group) and ameliorated the ratio of $\mathrm{RV} /(\mathrm{LV}+\mathrm{S})(0.34 \pm 0.03$; $\mathrm{P}<0.05$ vs. MCT group), suggesting that activation of PPAR $\gamma$ effectively suppressed the development of PAH.

Effects of PPAR $\gamma$ activation on MCT-induced pulmonary arterial remodeling. To determine the mechanisms underlying activation of PPAR $\gamma$ inhibition of PAH, remodeling of the pulmonary artery was examined using histological analysis. Fig. 2A and B show that medial MT and WA were significantly elevated in small pulmonary arterioles in MCT-treated rats compared with that of the control rats. This was accompanied with the increase in cell number of PASMCs in the medial layer of the small pulmonary artery, whereas treatment with rosiglitazone suppressed these changes in the pulmonary artery in MCT-treated rats (Fig. 2C), indicating that rosiglitazone inhibited 
A

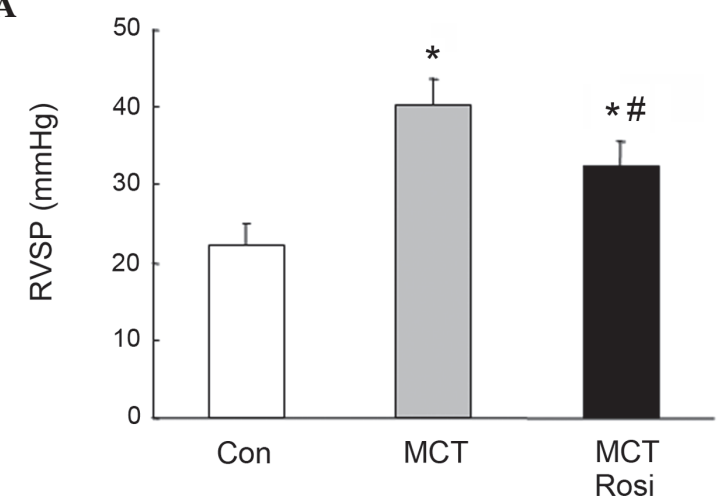

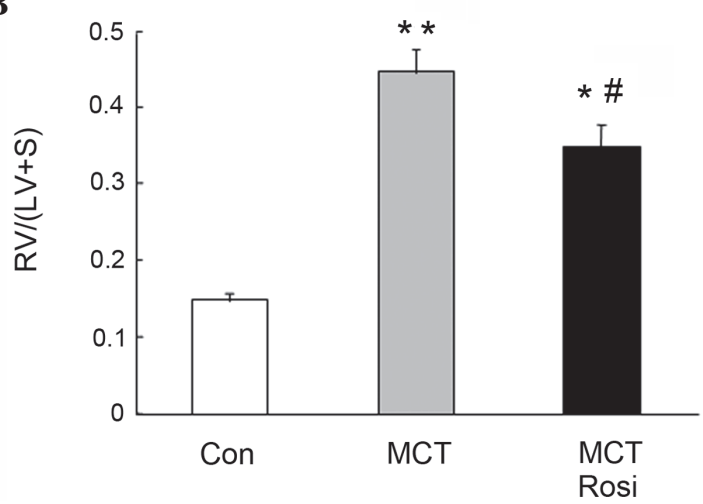

Figure 1. Rosgilitazone prevents progression of MCT-induced PAH in rats. (A) RVSP in each group. (B) Ratios of RV to LV plus septum weight [RV/(LV + S)] The RVSP and RV/(LV + S) ratio were markedly increased in MCT-induced PAH rats (MCT), while treatment with rosiglitazone (5 mg/kg/day) significantly reversed these changes (MCT + Rosi). All the values are mean \pm standard error of the mean. ${ }^{*} \mathrm{P}<0.05$ and ${ }^{* * *} \mathrm{P}<0.01$ vs. control; ${ }^{*} \mathrm{P}<0.05$ vs. MCT-treated group. Rosi, rosgilitazone; MCT, monocrotaline; PAH, pulmonary arterial hypertension; RVSP, right ventricle systolic pressure; RV, right ventricular; LV, left ventricle; Con, control.

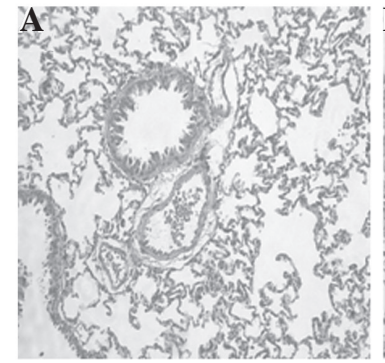

Con

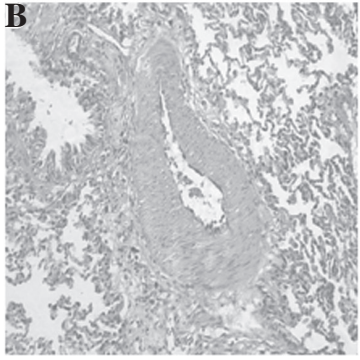

MCT

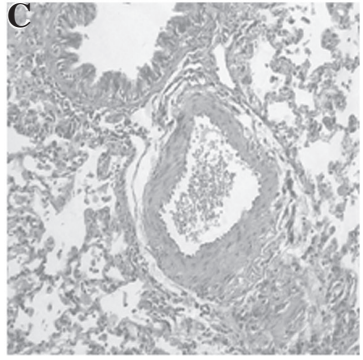

MCT+Rosi
D

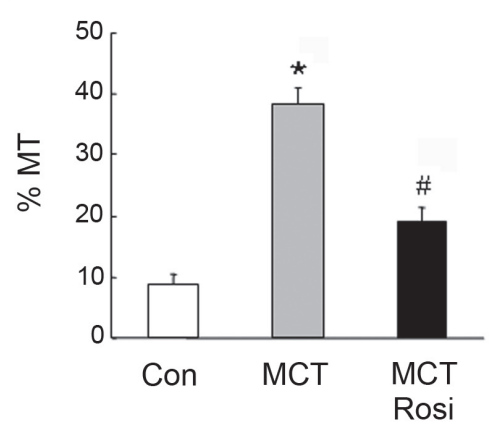

$\mathbf{E}$

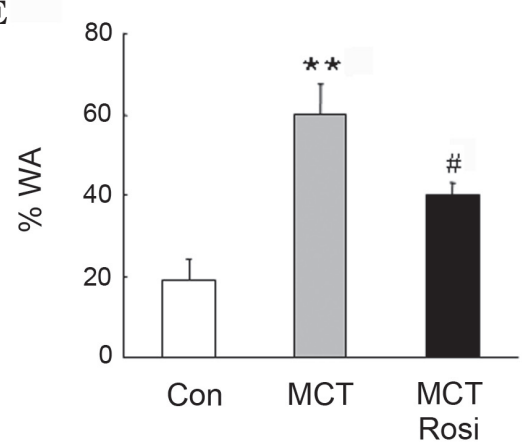

Figure 2. Pulmonary arteriole remodeling was attenuated by rosiglitazone in pulmonary arterial hypertension rats. Compared with the (A) control group, (B) MCT induced pulmonary vascular remodeling, (C) which was attenuated by rosiglitazone treatment (hematoxylin and eosin staining; original magnification, x200). The (D) \%MT and (E) \%WA were significantly decreased when administered with rosiglitazone (5 mg/kg/day) (n=6). Data represent mean \pm standard error of the mean. ${ }^{*} \mathrm{P}<0.05$ and ${ }^{* *} \mathrm{P}<0.01$ vs. control; ${ }^{*} \mathrm{P}<0.05$ vs. MCT-treated group. Rosi, rosiglitazone; MCT, monocrotaline; Con, control; $\% \mathrm{MT}$, percentage of medial wall thickness; \%WA, percentage of wall area.

pulmonary artery remodeling by suppressing the proliferation of PASMCs. Fig. 2D and E further indicated that \%MT and \%WA in rats of MCT-induced PAH were significantly increased, while the presence of rosiglitazone reduced these parameters in the PAH model (MCT + Rosi vs. MCT group, $\mathrm{P}<0.05$ ), suggesting that activation of PPAR $\gamma$ inhibited the pulmonary vascular remodeling in MCT-treated rats.

Mechanisms of activation of PPAR inhibiting PASMCs proliferation. Activation of the PI3K/Akt signaling pathway is associated with a variety of types of cells proliferation, including PASMCs. Therefore, it is important to know whether activation of PPAR $\gamma$ by rosiglitazone inhibits PASMCs proliferation through negative regulation of the PI3K/Akt pathway in intrapulmonary arteries. Fig. 3A shows that the phosphorylation of Akt was increased with a 3.29-fold compared with the control in MCT-treated rats, while the level of Akt phosphorylation decreased from a 3.29-fold to 2.27-fold increase over the control in the rosiglitazone-treated model of PAH (MCT + Rosi vs. MCT group, $\mathrm{P}<0.05)$, suggesting that activation of PPAR $\gamma$ suppresses the proliferation of PASMCs by modulating PI3K/Akt signaling. 
A
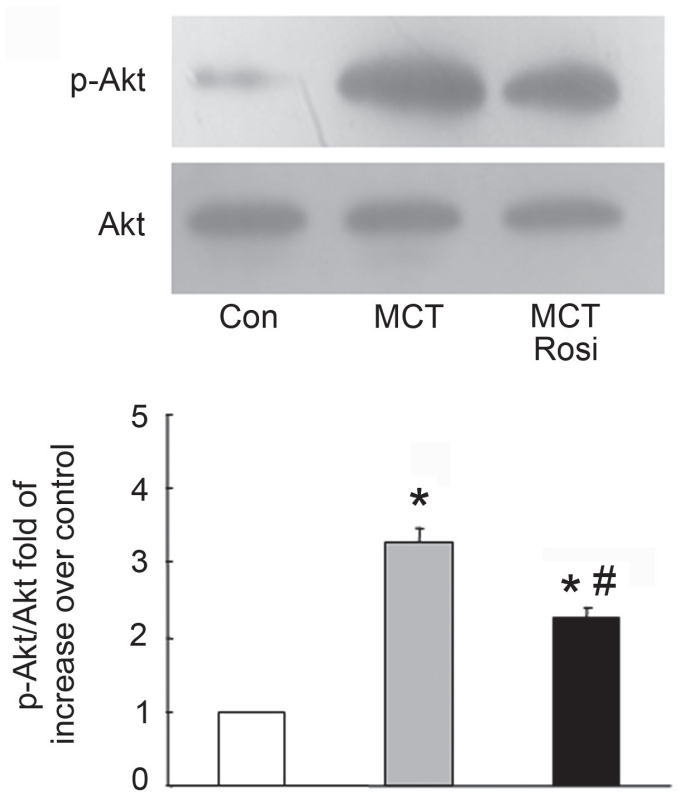

B
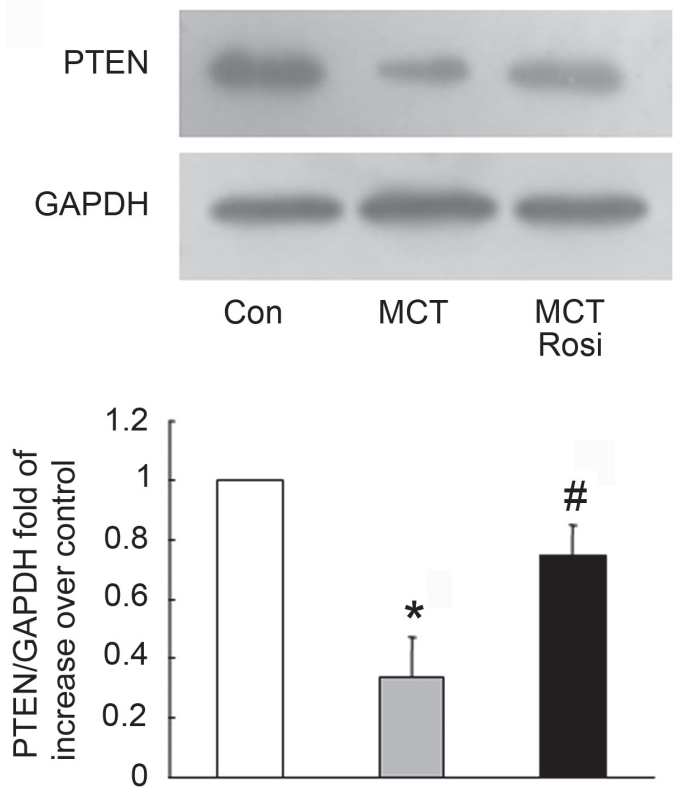

Figure 3. Rosiglitazone inhibits MCT-induced pulmonary arterial hypertension in rats by regulating the PTEN/PI3K/Akt signaling pathway. (A) MCT increased Akt serine-473 phosphorylation (p-Akt) as the fold-change increases when normalized to the total Akt expression, while these effects were blocked by rosiglitazone. Data represent mean \pm standard error of the mean (SEM) $(n=3$ in each group). (B) Western blotting of PTEN and GAPDH in the control, MCT and $\mathrm{MCT}+$ Rosi groups. The results show a significant decrease in PTEN expression after administration of a single dose of MCT $(60 \mathrm{mg} / \mathrm{kg})$, which was ameliorated by treatment with rosiglitazone $(5 \mathrm{mg} / \mathrm{kg} / \mathrm{day})$ for 4 weeks. Input GAPDH served as a loading control, data represent mean \pm SEM. ${ }^{*} \mathrm{P}<0.05$ vs. control; ${ }^{\text {"}} \mathrm{P}<0.05$ vs. MCT-treated group; $\mathrm{n}=3$ for each group). Rosi, rosiglitazone; PTEN, phosphatase and tensin homologue deleted on chromosome ten; Con, control; MCT, monocrotaline; PI3K, phosphatidylinositol 3-kinase.

To further clarify the mechanisms of activation of PPAR $\gamma$ negatively regulating PI3K/Akt cascade, the intrinsic negative regulator of PI3K, PTEN, was examined. As shown in Fig. 3B, the endogenous level of PTEN was lower than the control in the MCT-induced model of PAH (MCT vs. control, $\mathrm{P}<0.05$ ), while the co-treatment with rosiglitazone reversed the reduction of the PTEN protein level compared to the model of PAH (MCT + Rosi vs. MCT group, $\mathrm{P}<0.05$ ), indicating activation of PPAR $\gamma$ regulation of the PI3K/Akt pathway by upregulation of PTEN.

\section{Discussion}

The major finding of the present study is that activation of PPAR $\gamma$ by rosiglitazone significantly induced the expression of PTEN, which in turn inhibits the PI3K/Akt signaling pathway, mediates the proliferation of PASMCs and subsequently suppresses pulmonary vascular remodeling and the development of PAH. The study provides a novel molecular basis whereby activation of PPAR $\gamma$ modulates vascular remodeling and treats PAH.

Vascular remodeling is believed to be the major contributor during PAH, which is characterized by enhanced proliferation and migration of PASMCs. Several signaling pathways are associated with the growth and apoptosis of PASMCs during PAH $(12,13)$. For example, stimulation of human PASMCs with platelet-derived growth factor induced PI3K-dependent activation of Akt, p70 S6 kinase and ribosomal protein S6, suggesting that PI3K signaling is necessary to mediate human PASMCs proliferation and the activation of PI3K may play an important role in vascular remodeling (14). In the present study, the level of p-Akt significantly increased in rats with MCT-induced PAH, along with the elevation of RVSP and right ventricle hypertrophy. Furthermore, the H\&E staining showed that there was a significant increase of the proliferation of PASMCs and the vascular remodeling of pulmonary arteries in the MCT-treated group. Taken together, these results suggest that PI3K/Akt signaling pathway is responsible for the proliferation of PASMCs, pulmonary vascular remodeling and the development of PAH.

The PTEN tumor-suppressor gene is frequently mutated in numerous types of human cancer, such as pancreatic cancer, glioblastoma and lung cancer (15-17). Previous studies have suggested that PTEN not only regulates cardiomyocyte hypertrophy and survival, but also regulates pulmonary smooth muscle cell proliferation and cell survival $(18,19)$. Phosphatidylinositol 3-kinases (PI3Ks) are a subfamily of lipid kinases, which catalyze the formation of phosphatidylinositol-3,4,5-trisphosphate (PIP3) from phosphatidylinositol-4,5-bisphosphate (PIP2). The serine-threonine kinase Akt (also known as PKB) is a centrally important downstream effector of PIP3, which regulates proliferation, growth and survival $(20,21)$. Previous studies have shown that PTEN plays an important role in the pathogenesis of diabetes and numerous cancer diseases, and further study has indicated that induction of PTEN by activation of PPAR $\gamma$ inhibits the PI3K/Akt signaling pathway-mediated proliferation of tumor cells (22-25). The present study showed that the expression of PTEN was significantly decreased in the MCT-induced group, along with the activation of PI3K/Akt pathway, and the accelerated process of PASMCs proliferation and pulmonary vascular remodeling.

PPAR $\gamma$ is one of the ligand-activated nuclear hormone receptors of the steroid receptor, and it has been shown to be involved in lipid metabolism and glucose homeostasis (26). 
Previous studies indicate that PPAR $\gamma$ also regulates cellular proliferation and differentiation and anti-angiogenesis and anti-inflammatory functions (27-29). PTEN contains two PPAR $\gamma$ responsive elements within its promoter region, and PPAR $\gamma$ can bind to its putative PPAR response elements and regulate the expression of PTEN. Increasing evidence supports that the PPAR $\gamma$ agonists of the TZD class (rosiglitazone and troglitazone) inhibit PAH and pulmonary vascular remodeling in several experimental models of PAH (30-33). By contrast, targeted genetic deletion of PPAR $\gamma$ from endothelial or vascular smooth muscle cells is associated with the development of spontaneous PAH in mice (34-36). Furthermore, recent studies showed that activation of PPAR $\gamma$ reduces PAH through regulation of the ET-1 receptors or alteration in miR-27a and ET-1 levels $(37,38)$. The results of the present study found that rosiglitazone treatment decreased $\mathrm{RVSP}$ and the ratio of $\mathrm{RV} /(\mathrm{LV}+\mathrm{S})$ in MCT-induced PAH in rats, and \%MT and \%WA induced by MCT were also similarly decreased in MCT rats, which was associated with the induction of PTEN and suppression of PI3K/Akt signaling cascades. Taken together, the present results identify that the activation of PPAR $\gamma$ suppresses MCT-induced PAH in rats, at least partly, by the regulation of the PTEN/PI3K/Akt signaling pathway, suggesting that the therapeutic potential of strategies targeting PPAR $\gamma$ will be beneficial to treat PAH.

\section{Acknowledgements}

The present study was supported by the National Natural Science Foundation of China (grant no. 81070045) and the Key Clinical Project for Affiliated Hospital of Ministry of Public Health of China (grant no. 111).

\section{References}

1. Humbert M, Sitbon O and Simonneau G: Treatment of pulmonary arterial hypertension. N Engl J Med 351: 1425-1436, 2004.

2. Martens FM, Visseren FL, Lemay J, de Koning EJ and Rabelink TJ: Metabolic and additional vascular effects of thiazolidinediones. Drugs 62: 1463-1480, 2002.

3. Meng Y, Chen C, Tian C, Du J and Li HH: Angiotensin II-induced Egr-1 expression is suppressed by peroxisome proliferatoractivated receptor- $\gamma$ ligand $15 \mathrm{~d}_{-} \mathrm{PGJ}_{2}$ in macrophages. Cell Physiol Biochem 35: 689-698, 2015.

4. Gao D, Hao G, Meng Z, et al: Rosiglitzone Suppresses Angiotensin II-Induced Production of KLF5 and Cell Proliferation in Rat Vascular Smooth Muscle Cells. PLoS One 10: e0123724, 2015.

5. Nicola T, Ambalavanan N, Zhang W, et al: Hypoxia-induced inhibition of lung development is attenuated by the peroxisome proliferator-activated receptor- $\gamma$ agonist rosiglitazone. Am J Physiol Lung Cell Mol Physiol 301: L125-134, 2011.

6. Jiang C, Ting AT and Seed B: PPAR- $\gamma$ agonists inhibit production of monocyte inflammatory cytokines. Nature 391: 82-86, 1998.

7. Morales-Garcia JA, Luna-Medina R, Alfaro-Cervello C, Cortes-Canteli M, Santos A, Garcia-Verdugo JM and Perez-Castillo A: Peroxisome proliferator-activated receptor $\gamma$ ligands regulate neural stem cell proliferation and differentiation in vitro and in vivo. Glia 59: 293-307, 2011

8. Kulkarni AA, Thatcher TH, Olsen KC, Maggirwar SB, Phipps RP and Sime PJ: PPAR- $\gamma$ ligands repress TGF $\beta$-induced myofibroblast differentiation by targeting the PI3K/Akt pathway: Implications for therapy of fibrosis. PLoS One 6: e15909, 2011.

9. Nisbet RE, Bland JM, Kleinhenz DJ, Mitchell PO, Walp ER, Sutliff RL and Hart CM: Rosiglitazone attenuates chronic hypoxia-induced pulmonary hypertension in a mouse model. Am J Respir Cell Mol Biol 412: 482-490, 2010.
10. Ochoa CD, Yu L, Al-Ansari E, Hales CA and Quinn DA: Thrombospondin-1 null mice are resistant to hypoxia-induced pulmonary hypertension. J Cardiothorac Surg 5: 32, 2010.

11. Wang LX, Sun Y, Chen C, Huang XY, Lin Q, Qian GQ, Dong W and Chen YF: Effects and mechanism of oridonin on pulmonary hypertension induced by chronic hypoxia-hypercapnia in rats. Chin Med J (Engl) 122: 1380-1387, 2009.

12. Ismail S, Sturrock A, Wu P, Cahill B, Norman K, Huecksteadt T, Sanders K, Kennedy T and Hoidal J: NOX4 mediates hypoxia-induced proliferation of human pulmonary artery smooth muscle cells: The role of autocrine production of transforming growth factor- $\{\beta\} 1$ and insulin-like growth factor binding protein-3. Am J Physiol Lung Cell Mol Physiol 296: L489-L499, 2009.

13. Zhang D, Ma C, Li S, Ran Y, Chen J, Lu P, Shi S and Zhu D: Effect of Mitofusin 2 on smooth muscle cells proliferation in hypoxic pulmonary hypertension. Microvasc Res 84: 286-296, 2012.

14. Goncharova EA, Ammit AJ, Irani C, Carroll RG, Eszterhas AJ, Panettieri RA and Krymskaya VP: PI3K is required for proliferation and migration of human pulmonary vascular smooth muscle cells. Am J Physiol Lung Cell Mol Physiol 283: L354-L363, 2002.

15. Fenton TR, Nathanson D, Ponte de Albuquerque C, Kuga D, Iwanami A, Dang J, Yang H, Tanaka K, Oba-Shinjo SM, Uno M, et al: Resistance to EGF receptor inhibitors in glioblastoma mediated by phosphorylation of the PTEN tumor suppressor at tyrosine 240. Proc Natl Acad Sci USA 109: 14164-14169, 2012.

16. Ying H, Elpek KG, Vinjamoori A, Zimmerman SM, Chu GC, Yan H, Fletcher-Sananikone E, Zhang H, Liu Y, Wang W, et al: PTEN is a major tumor suppressor in pancreatic ductal adenocarcinoma and regulates an NF- $\kappa \mathrm{B}$-cytokine network. Cancer Discov 1: 158-169, 2011.

17. Zhang JG, Wang JJ, Zhao F, Liu Q, Jiang $\mathrm{K}$ and Yang GH: MicroRNA-21 (miR-21) represses tumor suppressor PTEN and promotes growth and invasion in non-small cell lung cancer (NSCLC). Clin Chim Acta 411: 846-852, 2010.

18. Oudit GY and Penninger JM: Cardiac regulation by phosphoinositide 3-kinases and PTEN. Cardiovasc Res 82: 250-260, 2009.

19. Oudit GY, Sun H, Kerfant BG, Crackower MA, Penninger JM and Backx PH: The role of phosphoinositide-3 kinase and PTEN in cardiovascular physiology and disease. J Mol Cell Cardiol 37: 449-471, 2004

20. Chen L, Monti S, Juszczynski P, Ouyang J, Chapuy B, Neuberg D, Doench JG, Bogusz AM, Habermann TM, Dogan A, et al: SYK inhibition modulates distinct PI3K/AKT- dependent survival pathways and cholesterol biosynthesis in diffuse large B cell lymphomas. Cancer Cell 23: 826-838, 2013.

21. De Luca A, Maiello MR, D'Alessio A, Pergameno M and Normanno N: The RAS/RAF/MEK/ERK and the PI3K/AKT signalling pathways: Role in cancer pathogenesis and implications for therapeutic approaches. Expert Opin Ther Targets 16 (Suppl 2): S17-S27, 2012.

22. Moon SH, Kim DK, Cha Y, Jeon I, Song J and Park KS: PI3K/Akt and Stat3 signaling regulated by PTEN control of the cancer stem cell population, proliferation and senescence in a glioblastoma cell line. Int J Oncol 42: 921-928, 2013.

23. Conley-LaComb MK, Saliganan A, Kandagatla P, Chen YQ, Cher ML and Chinni SR: PTEN loss mediated Akt activation promotes prostate tumor growth and metastasis via CXCL12/CXCR4 signaling. Mol Cancer 12: 85, 2013.

24. Akca H, Demiray A, Aslan M, Acikbas I and Tokgun O: Tumour suppressor PTEN enhanced enzyme activity of GPx, SOD and catalase by suppression of PI3K/AKT pathway in non-small cell lung cancer cell lines. J Enzyme Inhib Med Chem 28: 539-544, 2013.

25. Kitagishi $Y$ and Matsuda S: Redox regulation of tumor suppressor PTEN in cancer and aging (Review). Int J Mol Med 31: 511-515, 2013.

26. Monsalve FA, Pyarasani RD, Delgado-Lopez F and Moore-Carrasco R: Peroxisome proliferator-activated receptor targets for the treatment of metabolic diseases. Mediators Inflamm 2013: 549627, 2013.

27. Nickkho-Amiry M, McVey R and Holland C: Peroxisome proliferator-activated receptors modulate proliferation and angiogenesis in human endometrial carcinoma. Mol Cancer Res 10: 441-453, 2012.

28. O'Sullivan SE and Kendall DA: Cannabinoid activation of peroxisome proliferator-activated receptors: Potential for modulation of inflammatory disease. Immunobiology 215: 611-616, 2010. 
29. Robinson E and Grieve DJ: Significance of peroxisome proliferator-activated receptors in the cardiovascular system in health and disease. Pharmacol Ther 122: 246-263, 2009.

30. Stephen J, Delvecchio C, Spitale N, Giesler A, Radford K, Bilan P, Cox PG, Capone JP and Nair P: PPAR ligands decrease human airway smooth muscle cell migration and extracellular matrix synthesis. Eur Respir J 41: 425-432, 2013.

31. Wang H, Wu Q, Liu Z, Luo X, Fan Y, Liu Y, Zhang Y, Hua S, Fu Q, Zhao M, et al: Downregulation of FAP suppresses cell proliferation and metastasis through PTEN/PI3K/AKT and Ras-ERK signaling in oral squamous cell carcinoma. Cell Death Dis 5: e1155, 2014.

32. Crossno JT Jr, Garat CV, Reusch JE, Morris KG, Dempsey EC, McMurtry IF, Stenmark KR and Klemm DJ: Rosiglitazone attenuates hypoxia-induced pulmonary arterial remodeling. Am J Physiol Lung Cell Mol Physiol 292: L885-L897, 2007.

33. Zhang D, Wang G, Han D, Zhang Y, Xu J, Lu J, Li S, Xie X, Liu L, Dong L, et al: Activation of PPAR- $\gamma$ ameliorates pulmonary arterial hypertension via inducing heme oxygenase-1 and p21(WAF1): An in vivo study in rats. Life Sci 98: 39-43, 2014.

34. Nicol CJ, Adachi M, Akiyama TE and Gonzalez FJ: PPARgamma in endothelial cells influences high fat diet-induced hypertension. Am J Hypertens 18: 549-556, 2005.
35. Hansmann G, de Jesus Perez VA, Alastalo TP, Alvira CM, Guignabert C, Bekker JM, Schellong S, Urashima T, Wang L, Morrell NW, et al: An antiproliferative BMP-2/PPARgamma/apoE axis in human and murine SMCs and its role in pulmonary hypertension. J Clin Invest 118: 1846-1857, 2008.

36. Lu X, Bijli KM, Ramirez A, Murphy TC, Kleinhenz J and Hart CM: Hypoxia downregulates PPAR $\gamma$ via an ERK1/2-NF- $\kappa$ B-Nox4-dependent mechanism in human pulmonary artery smooth muscle cells. Free Radic Biol Med 63: 151-160, 2013.

37. Liu Y, Tian XY, Huang Y and Wang N: Rosiglitazone Attenuated Endothelin-1-Induced Vasoconstriction of Pulmonary Arteries in the Rat Model of Pulmonary Arterial Hypertension via Differential Regulation of ET-1 Receptors. PPAR Res 2014: 374075, 2014.

38. Kang BY, Park KK, Green DE, Bijli KM, Searles CD, Sutliff RL and Hart CM: Hypoxia mediates mutual repression between microRNA-27a and PPAR $\gamma$ in the pulmonary vasculature. PLoS One 8: e79503, 2013 